\title{
Original Article \\ Environmental Pressure from Pig Farming to Surface Water Quality Management in Yen Dung District Bac Giang Province
}

\author{
Ngo The An ${ }^{1, *}$, Ngo Phuong Lan ${ }^{2}$, Vo Huu Cong ${ }^{1}$, \\ Nong Huu Duong ${ }^{1}$, Nguyen Thi Huong Giang ${ }^{13}$, \\ ${ }^{1}$ Faculty of Environment, Vietnam National University of Agriculture, Trau Quy, Gia Lam, Hanoi, Vietnam \\ ${ }^{2}$ MSc student, Vietnam National University of Agriculture, Trau Quy, Gia Lam, Hanoi, Vietnam \\ ${ }^{3}$ PhD student, Vietnam National University of Agriculture, Trau Quy, Gia Lam, Hanoi, Vietnam
}

Received 31 January 2020

Revised 01 March 2020; Accepted 09 March 2020

\begin{abstract}
This study focuses on the environmental pressure of waste generated from pig farming in Yen Dung district. Terrain analysis of the digital elevation model (DEM) was used to delineate the sub-basin map where pollutants accumulated. Then we combined this map with land use map and statistical data for determining the distribution of pollutant discharged sources. Based on the pollution load coefficient prescribed by the Vietnam Environment Administration, the loads from all sources, including pig farming, were estimated for entire sub-basins within the district. The results show that the pollutant load from pig farming accounts for a large proportion and creates a major pressure on the local environment. The pollutant from pig farming greatly influences the spatial distribution of pollutant loads across sub-basins. Therefore, special attention should be paid to the waste management at pig farms (households and farm) to ensure the effectiveness of the environmental protection for the communities.
\end{abstract}

Keywords: livestock waste, pollutant load mapping, pig farming.

\section{Introduction}

Pig production has been condemned as a serious source of environmental pollution in many rural communities [1]. Provinces with high pig densities like Bac Giang have been the area of interest for many research on the pollution due to pig farming [2-4]. However, previous studies mainly focused on waste inventory and environmental quality assessment which was based on monitoring data. In fact, the pollutant is dispersed spatially in a regular manner, depending on the terrain and hydrological conditions. The spatial analysis of pollutant load

\footnotetext{
* Corresponding author.

E-mail address: ntan@vnua.edu.vn
}

https://doi.org/10.25073/2588-1094/vnuees.4552 
is therefore widely applied in many parts of the world [5,6]. Robinson et al. [7] conducted a global livestock distribution map for livestock management and environmental impacts at a coarse spatial resolution $\left(1 \mathrm{~km}^{2}\right)$. Gerber et al. [8] used national statistics to develop a livestock density map for Southeast Asia to manage the nutrient balance for agricultural land use. In Vietnam, there have been recent works focusing on the application of GIS in livestock research and livestock waste management. However, the above-mentioned research mainly refers to the statistics of cattle and poultry herds by administrative units or only considers the concentrated discharge points locally $[2,9]$. The research on the spatial distribution of waste according to the topographic conditions for pollution management in Vietnam is still rarely found nowadays.

Current spatial analysis software (namely ArcGIS, BASINS) has built-in terrain and hydrological analysis tools. These tools become very useful in supporting environmental decision making, especially when they are combined with specialized statistical software [10]. The application of the above-mentioned software in Vietnam is quite new and no specific studies have been applied to animal waste.
This study aimed to apply spatial analysis to estimate the pollutant load from pig farming and identify its pressure on environmental management in Yen Dung district. The hypothesis was tested is that the pollutant source from pig farming is significantly correlated and strongly influences the total pollutant load throughout the district. The research also explained why attention should be paid to controlling pig waste in communities and promoting waste treatment at sources for minimizing its spread on a large scale.

\section{Methods}

\section{Study areas and scope of the research}

The study was conducted in Yen Dung district, Bac Giang province which consists of 19 communes and 2 towns. In order to obtain the realistic model parameters, household surveys were conducted in 3 communes (Tan Lieu, Tien Dung and Quynh Son), representing communes with low $(0.7-0.9$ head/ha), medium (1.6-2.2 head/ha) and high (3.2-5.3 head/ha) pig density. The location map of the study area is shown in Fig. 1.
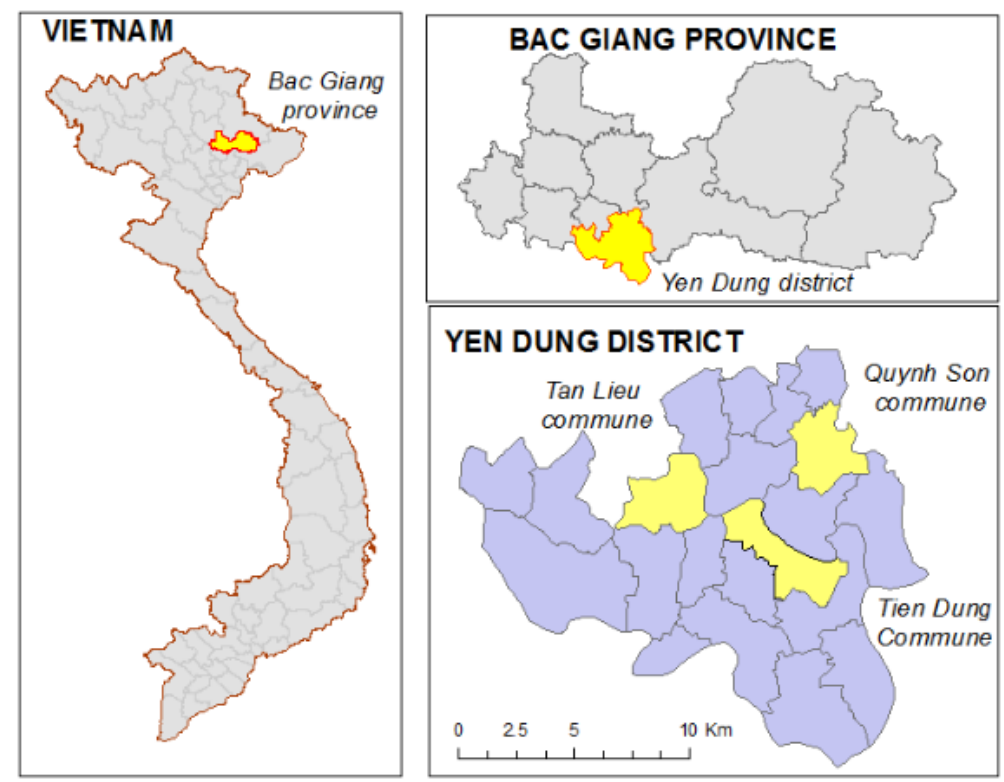

Fig. 1. Yen Dung District and 3 selected communes for household interviews. 


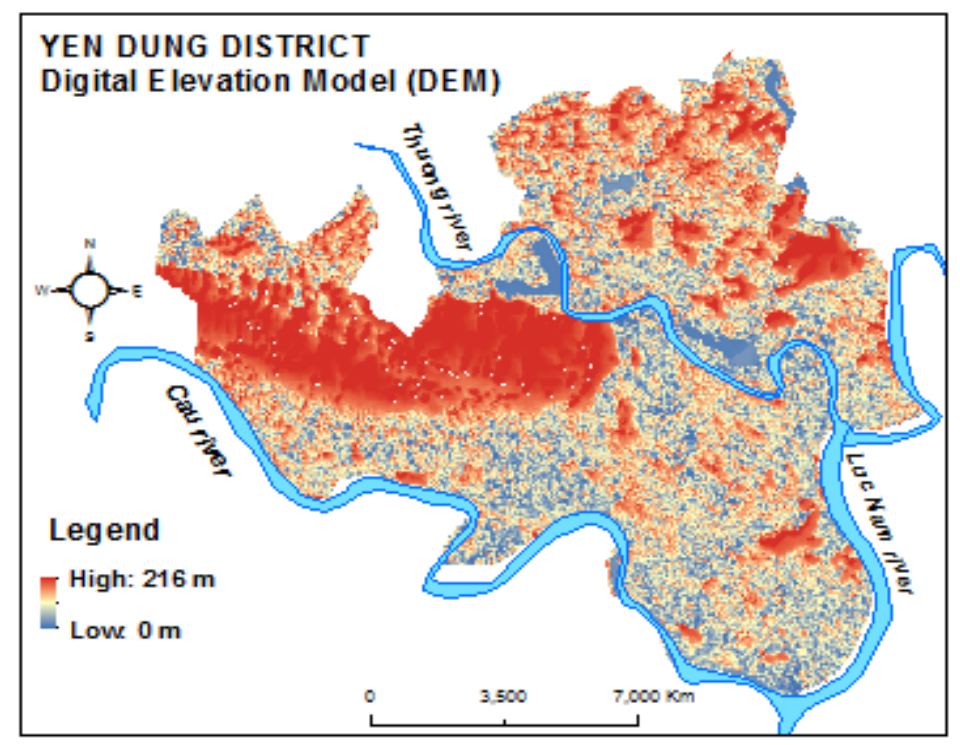

Fig. 2. DEM from SRTM image covering Yen Dung District.

Yen Dung is a semi-mountainous region surrounded by 3 rivers, namely Cau river, Thuong river, and Luc Nam river. The western part of the district has a high mountain range of over 216 m running through Noi Hoang, Yen Lu, Nham Son and Neo town. The remaining communes have low slopes and low-lying areas where the surface water is accumulated before discharging into river systems (Fig. 2). The hydrological flow spreads widely over the surface in the major direction from northwest to southeast.

This study focused mainly on pollutant load from pig farming, at household and farm level. However, other pollutant point sources such as industrial production facilities, services, hospitals and non-point sources (surface run-off) such as cultivation, forest, aquaculture, etc are also included for comparing and evaluating the pollutant load from different sources.

\section{Data sources for modeling}

Data used for modeling include:

- Farm characteristics, including about pig production scale and waste treatment technologies of each household, were collected from the household interviews being conducted in 2018 .

- Statistical data on livestock production (buffalo, cow, pig, and poultry) and population were collected from Yen Dung DARD and Bac Giang Statistical office (2018).

- Statistical data on industrial production facilities, services, businesses, and hospitals were collected from the Department of Planning and Investment of Bac Giang Province (2018).

- Satellite images, including DEM - SRTM 1 Arc-Second Global (September 23, 2014), Sentinel-2 L1C (April 9, 2018) and CNES highresolution images (2018), were used to delineate sub-basin and update land use map.

- Yen Dung district land use map (2015) was used as a based map for updating the 2018 land use map.

- Pollutant coefficients of major polluted sources were based on the Decision No. 154/QD-TCMT [11] which estimates COD, BOD, N-total and P-total load specifically for different animal and industries and land uses.

\section{Household interview}

The interview was conducted to collect information about farm characteristics and animal waste treatment at both households and farms. A total of 90 households of 3 typical communes were interviewed. At each commune, 30 households were randomly selected. Because the district has only 9 pig farms thus we interviewed in all farms. This data was later used 
as inputs for calculating the pollutant load of the whole district.

\section{Mapping and spatial analysis}

Study used ArcGIS 10.3 and Basins 4.5, the US-EPA software that was developed specifically for terrain analysis [12] to create the maps as followings.

Sub-basin delineation:

According to the Decision No.154/QDTCMT [11], the inventory of pollutant load should be carried out at the sub-basins levels. The data used to delineate sub-basin map is the DEM (SRTM 1 Arc-Second Global). Firstly, the image is filtered by the Fill-Sinks method [13] and then we calculated the flow direction and flow accumulation on each pixel using the Topdown Deterministic-8 method. The flow network from high to low levels plays an important role in determining the hierarchy of basins. In this research, we select the limit of flow detection within 100 ha (equivalent to the area of a village) to identify sub-basins using the automatic watershed delineation tool as suggested by Conrad et al. [14] and Fuliang et al. [6].

Mapping the distribution of pollutant sources:

Point sources:

Map of household locations was created using the "Create Random Points" tool in ArcGIS. The number of points in each residential cluster of the commune was created correspondingly to the number of households from the census. Attribute information, including the number of people, livestock (buffaloes, cows, pigs, and poultry), was assigned to each household based on the survey data (mean and standard error).

Maps of farms, industrial production facilities, services, and hospitals were created using the "Add XY data" function based on GPS coordinates and the survey data.

Non-point sources:

Non-point sources were identified based on the land-use map which is interpreted from Sentinel-2 satellite image by Unsupervised Segmentation method. The post-classification was adjusted and assigned class names based on information from the high-resolution CNES image (MapsGoogle) and land use map of Yen Dung district (2015). The accuracy of the classified map was assessed using the Kapa coefficient (Jensen, 1996). Land use types in the map were then assigned pollutant run-off coefficients for calculating total pollutant load according to Decision No. 154/QD-TCMT [11].

Estimation of pollutant load:

Pollutant load is calculated for each source on each sub-basin, then aggregated for the whole study area (Fig. 3). Pollutant load from pig farming was then calculated separately for analyzing its environmental pressure as followings.

Assessment of environmental pressure derived from pig farming

The pressure of pig farming push on the environment is the pollutant that contributes to the total load at each basin. The level of contribution was verified through Bayesian statistics (BIC) as suggested by modeling experts [15-18]. The BIC is calculated as follows (Schwarz, 1978).

$B I C=\ln (n) k-2 \ln (\hat{\mathrm{L}})$

where:

- $\hat{L}$ : the maximized value of the likelihood function

- $\mathrm{x}$ : the observed data

- $n$ : the number of data points or observations

- k: number of estimated parameters in the model

BIC values were calculated for each independent variable (pollutant loads from separate sources) and dependent variable (total pollutant load), using SPSS 16.0 software. If the load from pig farming is more significant than other sources, the BIC value of the model must be small, $\mathrm{R}^{2}$ must be high and the significant level must be acceptable $(\mathrm{p} \leq 0.1)$. According to the requirement of this test, data on total pollutant load was transformed by the ln function to ensure its normal distribution $[19,20]$. The acceptance ranges of the model that uses pollutant load from pig farming to predict total pollutant load across the district are expressed through the value $\Delta_{i}=\mathrm{BIC}_{i}-\mathrm{BIC}_{\text {min }}$; If $\Delta_{i}$ is from $0-2$, the model is considered authentic [21]. 


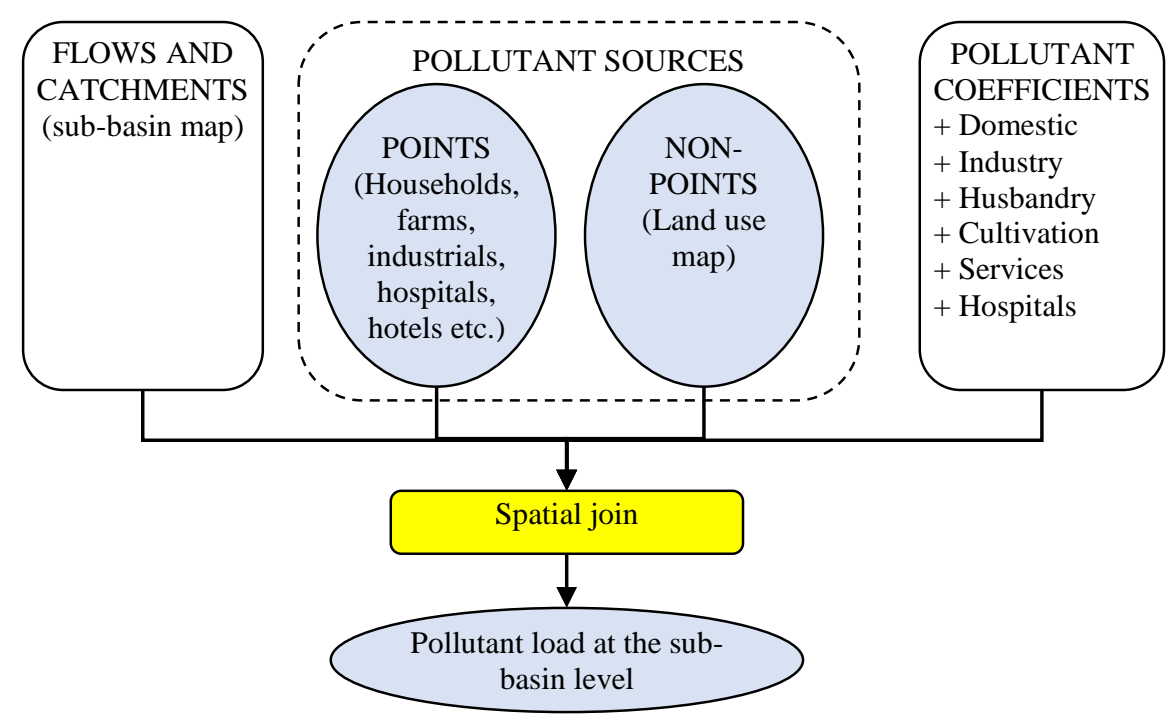

Fig. 3. Framework for calculating pollutant load by sub-basin.

\section{Results and Discussion}

\section{Current status of pig farming and environmental management}

Yen Dung district mainly has small-scale household pig production. In 2018, the district had 4,274 pig production households, with 82,313 pigs. There were only 9 pig farms with 7,225 heads, accounting for $8.8 \%$ of total pig production volume of the whole district [22].

Pig density in Yen Dung ranges from 0.7 to 5.3 heads/ha. The highest density is concentrated in Quynh Son commune (Fig. 4).

The current situation of environmental management, especially the management of animal waste in the study area, is still inadequate. Most pig waste is only partially treated by the mean of the biogas digester. According to survey data (2018), the percentage of pig households applying biogas was $63 \%$. Biogas treatment efficiency was over $80 \%$ (reduction of post biogas COD $=81 \%$; BOD5 = $86 \%)$. The untreated and post-biogas waste was discharged into the receiving water bodies such as fishponds, lakes and irrigation canals.

\section{Spatial distribution of pollutant sources}

The terrain analysis divided the study area into 3 sub-basins (level 1) associated with Cau
River, Luc Nam River and Thuong River. Subbasins were further divided into secondary subbasins (level 2). By setting the network delineation threshold method at 100 hectares (approximate an area of a village), Yen Dung district was divided into 153 sub-basin level 2 (Fig.5). Each sub-basin is considered as a sink that locally accumulated pollutants from discharged sources before discharging into three river systems.

The 2018 land use map was interpreted from satellite images as shown in Fig. 6. This map was adjusted and compared with CNES highresolution satellite images and the 2015 land use map. The accuracy evaluation provided the KAPA coefficient of 0.916 . This accuracy is relatively high [23] for further analysis.

Based on the location of residential clusters on the land use map (2018) and statistic data, the location of households and pollutant sources are generated as shown in Fig. 7.

When overlaying the locations of discharged sources with the sub-basin map, we got the number of pollution sources by sub-basins as in Table 1 .

Table 1 and Fig. 7 show that industrial production facilities located in the northwest sub-basin of Thuong River (Noi Hoang and Tien Phong commune) while other pollutant sources distributed sparsely over entire the district. 


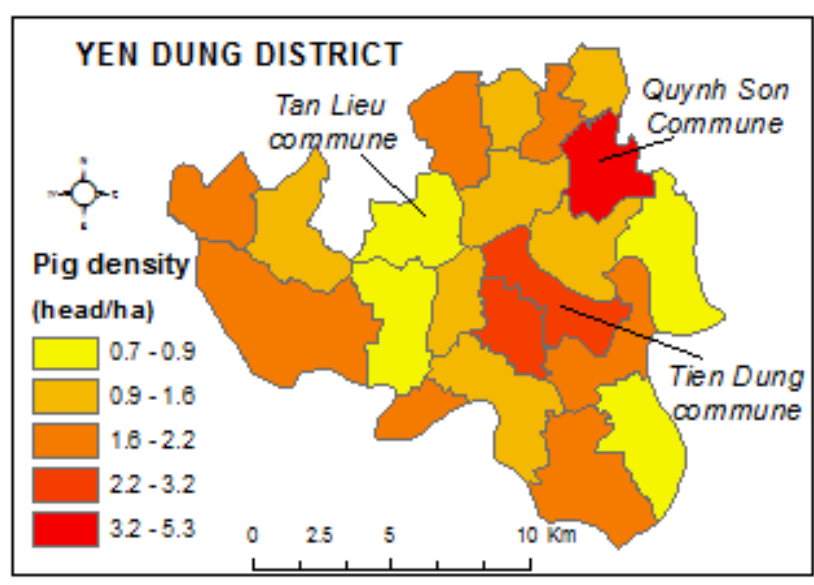

Fig. 4. Pig density by communes in 2018.

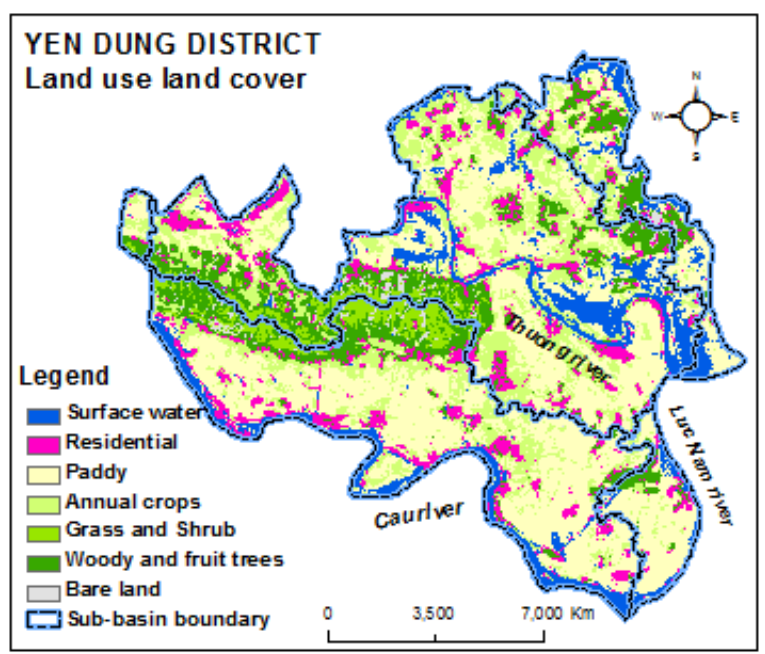

Fig. 6. Land use map of Yen Dung district in 2018.

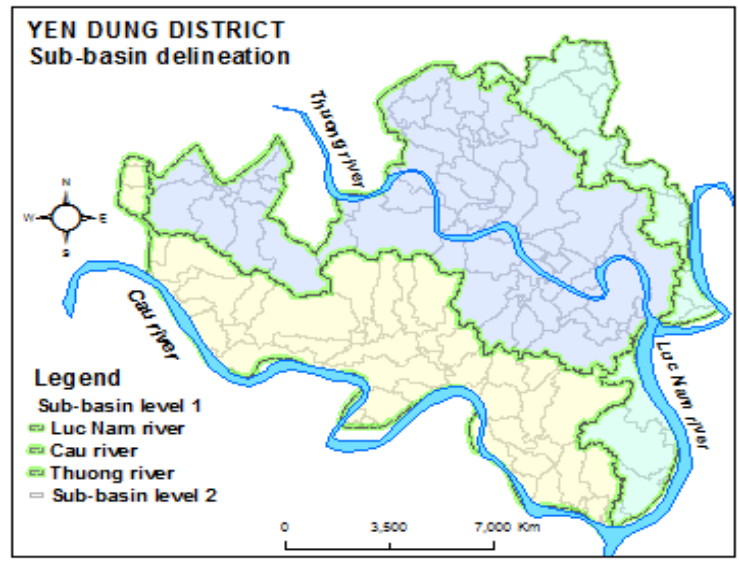

Fig. 5. Map of sub-basins in the study area.

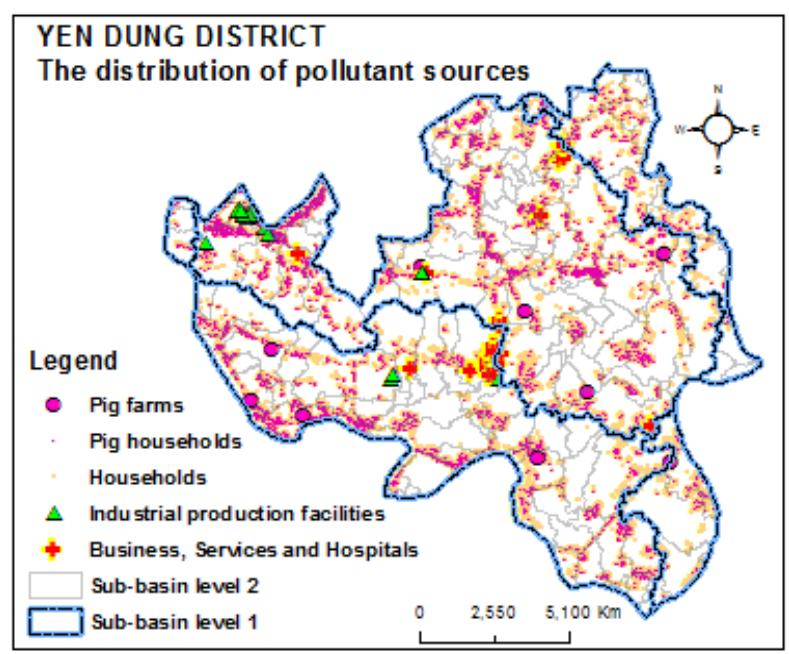

Fig. 7. Position of households created from land use map and statistics.

Table 1. Distribution of waste sources by sub-basins in Yen Dung district

\begin{tabular}{llrrrr}
\hline No. & Pollutant sources & $\begin{array}{r}\text { Luc Nam river } \\
\text { sub-basin }\end{array}$ & $\begin{array}{r}\text { Cau river } \\
\text { sub-basin }\end{array}$ & $\begin{array}{r}\text { Thuong river } \\
\text { sub-basin }\end{array}$ & All district \\
\hline 1 & Number of households & 5,566 & 12,395 & 20,025 & 37,986 \\
& 10,707 & 29,917 & 41,689 & 82,313 \\
& Pig (head) & 18,632 & 43,722 & 72,681 & 135,035 \\
& Population (person) & 17,065 & 16,003 & 32,216 & 65,281 \\
& Other animals (head) & 1 & 4 & 4 & 9 \\
\hline 2 & Pig farms (farm) & 300 & 1725 & 5200 & 7225 \\
\hline Pig (head) & 0 & 3 & 33 & 36 \\
\hline 3 & Number of industrial & & & & 23 \\
& production facilities & 2 & 11 & 10 & \\
\hline 4 & Number of businesses, services, & & & & 19030 \\
& and hospitals & 2918 & 6960.2 & 9151.4 & 153 \\
\hline 5 & Land uses run-off (ha) & 29 & 58 & 66 & 153 \\
\hline & Number of sub-basin -level 2 & & & &
\end{tabular}


Table 2. Pollutant load from major sources in Yen Dung district

\begin{tabular}{lllll}
\hline \multirow{2}{*}{ Pollution load } & \multicolumn{4}{c}{ Parameters (ton/year) } \\
\cline { 2 - 5 } & COD & BOD $_{5}$ & N-total & P-total \\
\hline Point sources: & $2338.2(37 \%)$ & $1311.3(38 \%)$ & $291.0(32 \%)$ & $91.7(51 \%)$ \\
Pig farming & 1269.5 & 672.1 & 44.8 & 12.6 \\
Human living & 1420.2 & 789.5 & 279.0 & 52.0 \\
Other animals & 63.8 & 21.3 & 17.0 & 2.6 \\
Industry & 4 & 2.1 & 2.1 & 0.4 \\
Business, hospitals & & & & \\
Non-point sources: & & 703.6 & 276.5 & 21.4 \\
Land use types & 1265.8 & 3499.8 & 910.4 & 180.7 \\
\hline Total pollution load: & 6362.2 & & & \\
\hline
\end{tabular}

\section{Pollutant load in Yen Dung district}

The total pollution load calculated according to 4 basic environmental parameters for different sources is presented in Table 2.

According to the table above, the pollution load from pig production (households and farms) accounts for $32-51 \%$ compared to the sums of 6 main sources. It indicates that this source creates the greatest pressure for environmental management in the study area if there is no proper treatment was applied.

The distribution of pollutants over subbasins is presented as maps in Fig. 8. In these maps, darker the color represents the higher pollutant load accumulated in the sub-basins. Particularly, the highest pollutant load concentrated in some residential areas of Tien Phong, Yen Lu, Tu Thuong, Dong Viet, Duc Giang, and Xuan Phu communes.

\section{Environmental pressure from pig farming}

As mentioned above, the amount of pollutants from pig production calculated according to parameters $\mathrm{COD}, \mathrm{BOD}_{5}, \mathrm{P}$-total, $\mathrm{N}$ total accounts for $32-51 \%$ of the total load on the district. The results of statistical analysis demonstrate clearly the strong relationship between pollutant load from pig farming and total load (correlation coefficient $\mathrm{R}^{2}>0.9 ; \mathrm{p}=0$ for all 4 parameters).

The visual comparison among 04 maps (Fig. 9) also reveals a high consensus with statistical analysis as almost all dark color areas from the map representing total pollutant load (map A, B) are also found in the dark color from the map representing pollutant from pig farming (map C, D). The pollutant distribution trend over the map is quite similar. The only difference among maps can find in some sub-basins in Tan Lieu and Tri Yen communes. The reason for the difference is a high density of pig farms located near the residential clusters of Tan Lieu commune while there are few pig farms in sub-basins of Tri Yen commune.

The environment pressure derived from pig farming compared to that of other sources is also analyzed through the BIC statistical analysis with two typical parameters: $\mathrm{COD}$ and $\mathrm{BOD}_{5}$ (Table 3). The data for BIC included dependent variables i.e. total pollutant loads ( $\ln \mathrm{COD}$ and $\left.\ln \mathrm{BOD}_{5}\right)$ which were predicted based on independent variables i.e. pollutant load from individual sources (Table 3).

According to the data in Table 3, only the independent variable "Pig farming" satisfies the acceptable level of statistical significance $(p=$ $0,102)$. The BIC statistic of this variable is also the lowest among the variables included in the model. In this case, $\mathrm{BIC}_{\min }=\mathrm{BIC}$ "pig farming" and $\Delta_{\mathrm{i}}$ $=\mathrm{BIC}_{\mathrm{i}}-\mathrm{BIC}_{\min }=0$, for the case of $i=$ "pig farming"; therefore, the model (forecasting total pollutant load from pig farming) is statistically accepted. The value of $R^{2}>0.6$, indicates that over $60 \%$ of the variation in pollutant load among sub-basins can be explained by the variation of the load accumulated from pig farming. This result confirms that the pollutant load from pig farming has an important contribution to the environmental pressure in the study area. Therefore, special attention should be paid to control this source of pollutants for better environmental protection plan of the district. 

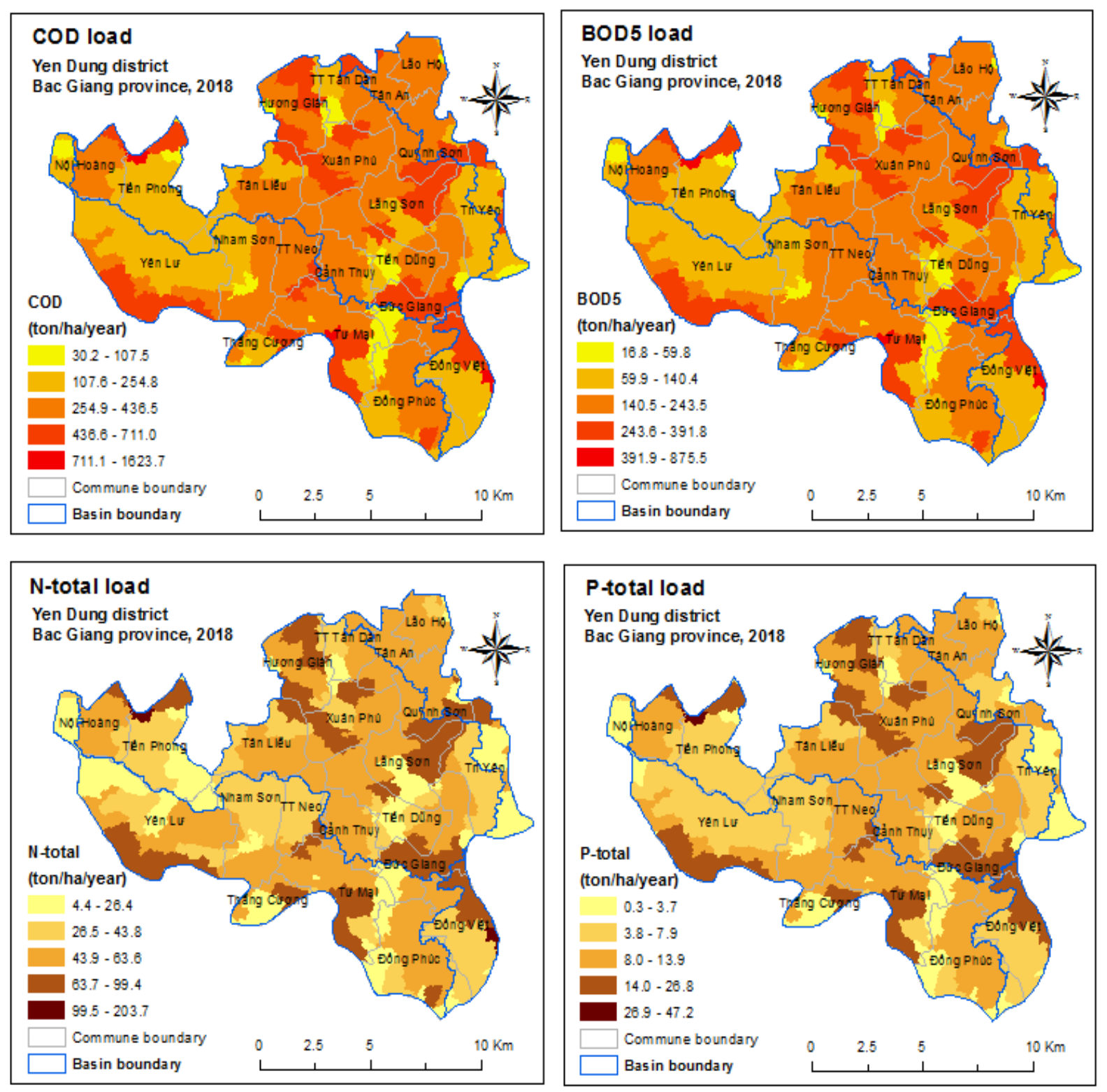

Fig. 8. Maps of pollutant load distribution in Yen Dung district.

The spatial distribution patterns of pollutant in the maps is clearly not a random trend. Within the communes, pollutant accumulated highly at the residential clusters and the farms. The pollutant load is also concentrated in low elevation sub-basins e.g. Yen Lu commune has the high load (dark color) in sub-basin near Cau river while other areas is bright color. This finding suggests that environmental management cannot be merely applied according to administrative units but needs to be area specific depending on actual load and loading capacity of the sub-basins. 

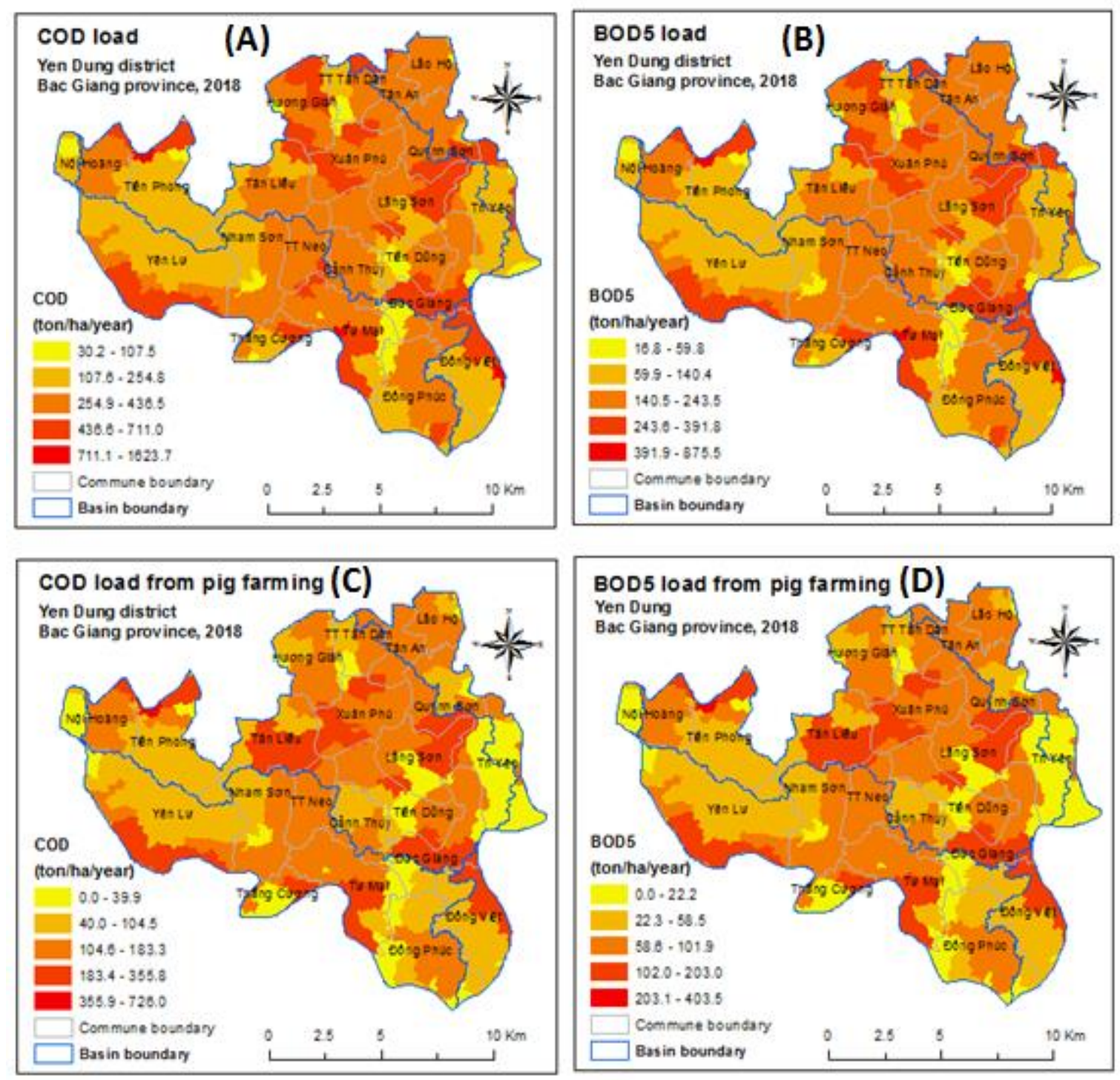

Fig. 9. Comparison between the pollutant loads from the total load (A, B) and pig farming (C, D).

Table 3. BIC analysis on the contribution of different pollutant sources to total load

\begin{tabular}{lllllll}
\hline Pollutant sources & \multicolumn{7}{c}{ COD } & \multicolumn{5}{c}{ BOD $_{5}$} \\
\cline { 2 - 7 } (Independent variables) & $R^{2}$ & BIC & Sig. $(p)$ & $R^{2}$ & BIC & Sig. $(p)$ \\
\hline Pig farming & 0.615 & -1.295 & 0.089 & 0.616 & -1.304 & 0.102 \\
Living activities (pop.) & 0.602 & -1.260 & 0.573 & 0.598 & -1.259 & 0.583 \\
Other animals & 0.586 & -1.160 & 0.917 & 0.588 & -1.172 & 0.930 \\
Land uses & 0.000 & -0.378 & 0.900 & 0.000 & -0.387 & 0.901 \\
Industrial production & 0.027 & -0.366 & 0.962 & 0.000 & -0.387 & 0.901 \\
Services, hospitals & 0.000 & -0.378 & 0.900 & 0.000 & -0.387 & 0.901 \\
\hline
\end{tabular}




\section{Conclusions}

Pollution load from pig farming estimated based on spatial analysis, using coefficients stated in Decision No.154/QD-TCM for Yen Dung district provided a result of 2338.2 (COD); $1311.3\left(\mathrm{BOD}_{5}\right) ; 291.0(\mathrm{~N}$-total) and $91.7(\mathrm{P}-$ total) tons/year. Compared to the total pollutant load, the source of pollutant from pig farming accounts for a large proportion, from 32-51\%.

Pollutant sources from pig farming influence significantly the spatial distribution of pollutant load over sub-basins. Statistical coefficient $\mathrm{R}^{2}>$ 0.6 proves that spatial variation in the pollutant load over sub-basins was due to the pollutant generated from pig farming. The statistical coefficient BICs calculated from the model that predicts total pollutant load based on pig farming also reveal that controlling pollutant generated from pig farming is the most important role in the environmental management for the district. These findings suggest that a special attention need to be paid to the waste management in pig production sector, including both household and big farm scales for ensuring the effectiveness of environmental protection at the locality.

This study focused only on pollutant load calculated based on factors stated by VEA (2019). Hazardous waste such as dead animals in case of disease has not been mentioned. Therefore, the calculated results do not fully reflect the hazardous and environmental pressure in special cases. Furthermore, factors currently being applied for estimating pollutant load equally across the district. This is also a limitation because it has not yet simulated spatial differences in waste disposal behavior of the dischargers. By applying some modern approaches such as agent-based modelling, it can solve the limitations mentioned above. It is a subject that the authors will present in another paper.

\section{Acknowledgements}

This research is funded by Vietnam National Foundation for Science and Technology
Development (NAFOSTED) under grant number 105.99-2018.318.

This paper also used the survey data from ARES AI Program with VNUA (2014-2019) Contract number: 04-DAVB/2019.

\section{References}

[1] MONRE, Rural environment: Country environment report 2014, Ministry of Natural resource and Environment (MONRE), Hanoi, 2014.

[2] Nguyen Thanh Thao, Duong Thi Hanh, Le Trung Viet, Nguyen Quang Trung, Application of AIQSDB software for analyzing organic compounds in wastewater in pig farms in Bac Giang province, Bio-physio chemistry analysis journal 21 (2016) 19-24.

[3] T.K.V. Vu, M.T. Tran, T.T.S. Dang, A survey of manure management on pig farms in Northern Vietnam, Livestock Science 112 (2007) 288-297. https://doi.org/10.1016/j.livsci.2007.09.008.

[4] N. Pham, T. Kuyama, T.H.V. Dinh, T.S. Cao, C.H. Vo, Situation Analysis on Pig Manure and Effluent Management in Vietnam, WEPA Action Programme in Vietnam, Tokyo, 2017.

[5] T.P. Tee, J.B. Liang, E.S. Chew, Z.A. Jelan, T.C. Loh, P. Loganathan, Mapping waste distribution in intensive pig production areas using GIS, O/4'h International Livestock Waste Management Symposium, Penang, 2002.

[6] Fuliang Deng, Tao Lin, Yue Zhao, Ying Yuan, Zoning and Analysis of Control Units for Water Pollution Control in the Yangtze River Basin, China, Sustainability 9 (2017) e1374. https://doi.org/ 10.3390/su9081374.

[7] T.P. Robinson, G. R.W. Wint, G. Conchedda, T.P. Van Boeckel, V. Ercoli, E. Palamara, G. Cinardi, L. D'Aietti, S.I. Hay, M. Gilbert, Mapping the global distribution of livestock. PloS one, 9 (2014) e96084. https://doi.org/10.1371/journal.pone.009 6084.

[8] P. Gerber, P. Chilonda, G. Franceschini, H. Menzi, Geographical trends in livestock densities and nutrient balances in South, East and South-East Asia, Livestock Environment and Development Initiative (LEAD), FAO, Rome, 2005.

[9] Nguyen Thi Thoai Nghi, Application of GIS for management of waste sources from livestock raising and slaughtering activities in $\mathrm{O}$ Mon District Can Tho City, Can Tho University, Can Tho, 2017.

[10] Ngo The An, Tran Nguyen Bang, Modelling for Environmental management, Vietnam Education publishing house, Hanoi, 2015. 
[11] VEA, Decision number 154/QĐ-TCMT dated $15 / 2 / 2019$ re. Issueing technical guideline on estimating Total maximal dialy load of rever water, Vietnam Environment Administration (VEA), Honoi, 2019.

[12] J.P. Wilson, Environmental Applications of Digital Terrain Modeling, Wiley-Blackwell Press, New Jersey, 2018.

[13] L. Wang, H. Liu, An efficient method for identifying and filling surface depressions in digital elevation models for hydrologic analysis and modelling, Geographical Information Science 20 (2006) 193-213. https://doi.org/10.1080/1365 8810500433453.

[14] O. Conrad, B. Bechtel, M. Bock, H. Dietrich, E. Fischer, L. Gerlitz, J. Wehberg, V. Wichmann, J. Böhner, System for Automated Geoscientific Analyses (SAGA), Geoscientific Model Development Discussions 8 (2015) 2271-2312. https://doi.org/10.5194/gmd-8-1991-2015.

[15] R. Rebba, S. Huang, Y. Liu, S. Mahadevan, Statistical validation of simulation models, Materials and Product Technology 25 (2006) 164181.http://www.scopus.com/inward/record.url?sc $\mathrm{p}=31144478884 \&$ partnerID=8YFLogxK.

[16] P.C. Kleijnen, Validation of models: statistical techniques and data availability, Proceedings of the 31st conference on Winter simulation: Simulation a bridge to the future 1 (1999) 647654. https://doi.org/10.1145/324138.324450.
[17] F.A.A. Kingdom, N. Prins, Model comparison Psychophysics (Second Edition): A Practical Introduction, Elsevier Ltd, Amsterdam, 2016.

[18] J. Long, C. Robertson, Comparing spatial patterns. Geography Compass 12 (2017) e12356. https:// doi.org/10.1111/gec3.12356.

[19] S. Ferson, W.L. Oberkampf, L. Ginzburg, Model validation and predictive capability for the thermal challenge problem, Computer Methods in Applied Mechanics and Engineering 197 (2008) 24082430. https://doi.org/10.1016/j.cma.2007.07.030.

[20] Xuyuan Liu, Statistical validation and calibration of computer models, School of Industrial and Systems Engineering Georgia Institute of Technology, Georgia, 2011.

[21] R.E. Kass, A.E. Raftery, Bayes Factors, Journal of the American Statistical Association 90 (1995) 773-795. https://doi.org/10.1080/01621459.1995. 10476572.

[22] Bac Giang DAV, Report on Animal production of Bac Giang province, Bac Giang Departnemt of Animal husbandry and Veterinary (DAV), Bac Giang province, 2018.

[23] J.R. Landis, G.G. Koch, The Measurement of Observer Agreement for Categorical Data. Biometrics 33 (1977) 159-174. https://doi.org/ 10.2307/2529310. 